\title{
Pandora: de Hesíodo a Calderón. Autores y textos en la tradición del mito
}

\author{
Jesús LÓPEZ ZAMORA \\ I.E.S. Profesor Emilio Lledó \\ Numancia de la Sagra (Toledo) \\ je_lo_za@hotmail.com
}

Recibido: 12-11-2013

Aceptado: 27-12-2013

\section{RESUMEN}

El objetivo del presente artículo es recorrer los principales autores, textos, interpretaciones y lecturas que conformaron el mito de Pandora desde la Antigüedad hasta su recepción en los siglos XVI y XVII, en especial entre los literatos del siglo de Oro español (Gracián y Calderón). Mostramos cómo el hipotexto hesiódico del relato ha sido transformado desde la propia Antigüedad por lecturas alegóricas, moralizantes, contaminationes, etc., haciéndolo campo fértil para la variación e innovación en sus elementos narrativos e iconográficos.

Palabras clave: Pandora, Hesíodo, recepción, contaminatio, Gracián, Calderón.

\begin{abstract}
The aim of this article is to explore main authors, texts, interpretations and readings that shaped Pandora myth from antiquity to its reception in the sixteenth and seventeenth centuries, especially among the writers of the Spanish Golden Age (Gracian and Calderon). It is showed Hesiodic hypotext has been transformed since the ancient times for allegorical like moralizing readings, contaminationes, etc., promoting thereby the change and innovation in their narrative and iconographic elements.
\end{abstract}

Keywords: Pandora, Hesiod, reception, contaminatio, Gracian, Calderon.

\section{SUMARIO}

1. Proemio. 2. Pandora: fuentes antiguas. 3. Pandora: fuentes secundarias del s. XVI. 4. Pandora: su recepción en la literatura del Siglo de Oro. 5. Epílogo.

\section{PROEMIO}

Pandora, la primera mujer según la mitología griega, está entre los personajes más significativos del pensamiento y de la literatura antigua. La recepción que de ella se hace entre los literatos desde la Antigüedad tardía no se corresponde con la relevancia que tuvo entre los autores clásicos, especialmente, entre los griegos. Es un 
hecho sorprendente. Motivos de este yermo literario desde el Medievo a los siglos $\mathrm{XV}-\mathrm{XVI}$, en especial en las Letras castellanas, podrían ser varios: el principal, en nuestra opinión, es que la Pandora pagana había quedado oculta casi por completo por la figura de la Eva bíblica; desde un punto de vista teológico, además, era una leyenda problemática, pues presenta a un dios creador, Zeus, que había de soslayarse; por otro lado, la lectura moral que fácilmente se desprendía de ella, a saber: el origen del mal en el mundo y la existencia de una esperanza para el hombre, eran aspectos que la doctrina cristiana tenía sustentados sólidamente sin necesidad de recurrir a las fuentes grecolatinas. El apologeta Tertuliano (De corona militis 7.84B-85A [ed. Migne]) lo expresaba así:

Litterce ad hoc sceculares necessarice; de suis enim instrumentis scecularia probari necesse est. quantulas attigi, credo sufficient. si fuit aliqua Pandora, quam primam fominarum memorat Hesiodus, hoc primum caput coronatum est a Charitibus, cum ab omnibus muneraretur unde Pandora. nobis uero Moyses propheticus, non poeticus pastor, principem fominam Euam facilius pudenda foliis, quam tempora floribus, incinctam describit. nulla ergo Pandora.

Vlpius Franekerensis Frisius, humanista holandés al que debemos una de las primeras traducciones de los Trabajos y Días de Hesíodo, expone esta interpretación de forma inequívoca (1539: fol. E8v, p. 80): «Eua nostra fuit Pandora».

En las páginas que siguen nos acercaremos a las fuentes clásicas del mito y a las que, ya en los siglos XV y, especialmente, XVI, recogieron los elementos constitutivos de la leyenda; finalmente, veremos su recepción, modestísima, en la literatura castellana del Siglo de Oro.

\section{PANDORA: FUENTES ANTIGUAS}

\subsection{Hesíodo (s. VIII a.C.), Op. 94-99}

Los elementos literarios, mitográficos e iconográficos que configuran el hipotexto del relato de Pandora desde la Antigüedad tienen en los poemas hesiódicos su génesis. Si bien en Teogonía 535-616 Hesíodo traza un primer esbozo de Pandora, el núcleo del mito se presenta en Trabajos y Días 94-99 (ed. Solmsen):

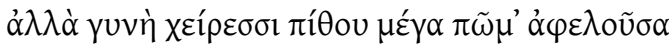

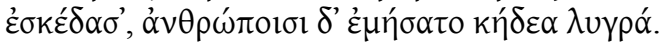

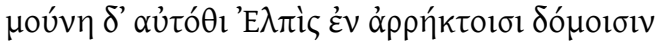

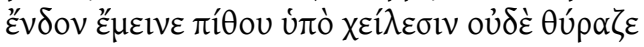

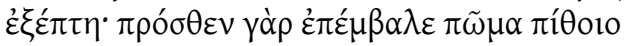

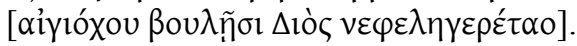

Pero aquella mujer, al quitar con sus manos la gran tapa de la tina los dispersó y preparó para los hombres tristes calamidades. Únicamente quedó dentro la Esperanza, 
entre sus indestructibles paredes bajo los bordes de la tinaja, y no salió volando hacia la puerta, pues antes Pandora le puso la tapa de la tinaja, por voluntad de Zeus portador de la égida y amontonador de nubes ${ }^{1}$.

Presentamos la versión de la profesora Corbera por ser modélica en su fidelidad al texto de Hesíodo. En este caso, la interpretación precisa de todos los elementos narrativos e iconográficos se antoja indispensable: 1) Pandora es la protagonista del relato,

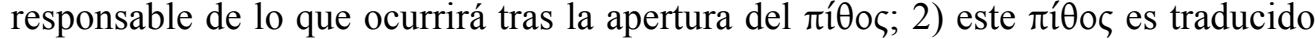
con gran corrección como tinaja; 3 ) males son, sin lugar a dudas, los inquilinos de aquella tinaja; 4) uno solo no escapa volando, la esperanza ( $\left.\dot{\varepsilon} \lambda \pi^{i} \varsigma^{\prime}\right)$. Éstos son, por lo tanto, los motivos con los que Hesíodo teje el primer texto que transmite el relato de Pandora y que se convierte, por tanto, en hipotexto al que habrán de mirar los autores posteriores.

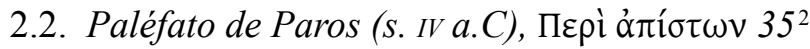

Paléfato, paradoxógrafo, reunió en un compendio mitográfico de marcada tendencia evemerista los principales mitos heredados: no cabe duda, la ingenuidad de Paléfato llega a la caricatura en el caso de su interpretación de Pandora:

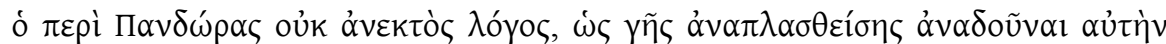

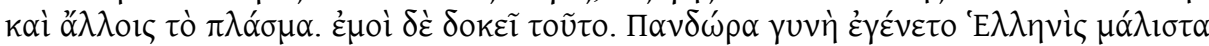

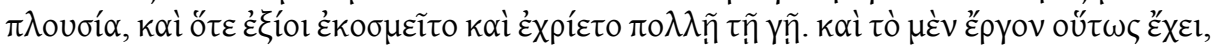

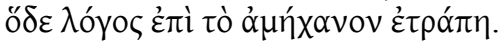

El mito de Pandora no es tolerable, como si, tras ser modelada la tierra, ella le diera forma a las demás cosas. Mi opinión es ésta: Pandora fue una mujer helena extraordinariamente rica, que, al salir de casa, se adornaba y ungía con mucha tierra ${ }^{3}$. Esta es la realidad, pero el mito ha derivado en lo extraordinario.

Otros autores y textos han podido, sin duda, enriquecer la interpretación del mito mejor que el propio Paléfato: no podemos olvidar las versiones tardías que, mediante el lenguaje de la fábula, recrean el texto hesiódico. Por medio de Esopo y de Babrio el mito de Pandora adoptó nueva forma, desdeñando la complejidad plasmada por Hesíodo, pues estos autores reducirán el contenido de la vasija a bienes, salvando así el escollo interpretativo.

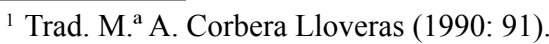

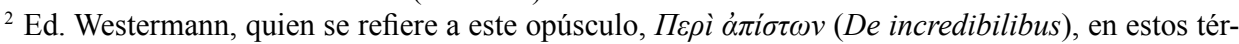
minos: scilicet idoneus esse uidebatur libellus ad puerilem institutionem (1843: xi).

${ }^{3}$ Es decir, con polvos o afeites elaborados con tierras.
} 


\subsection{Esopo (I a. C.), 1324}

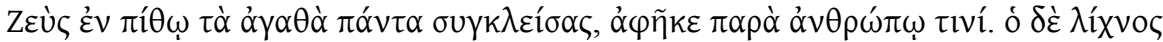

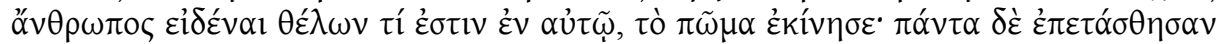

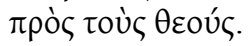
$\delta \omega ́ \sigma \varepsilon ı v$.

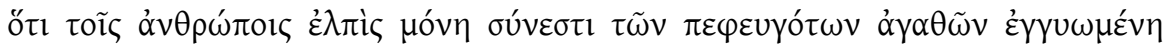

El texto de Esopo introduce dos novedades que serán recogidas por autores posteriores: una, no hay huella de males en el ríloc; otra, de menor influencia en las recreaciones que seguirán, es la ausencia de la propia Pandora, sustituida en el relato

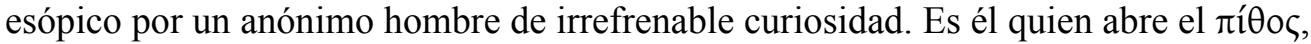
y el mal en el mundo no se debe a la turba que de allí irrumpe, sino, por el contrario, a que los bienes vuelan de regreso a los dioses. Así, «... para los hombres es la esperanza la única de los bienes huidos que promete a los hombres darlos», concluye la fábula, con evidente deseo de rememorar las palabras de Hesíodo 5 .

\subsection{Babrio (s. I d.C.), 586}

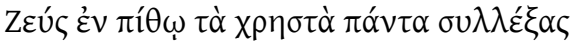

हैं

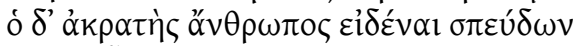

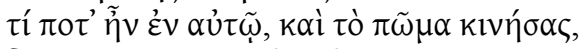

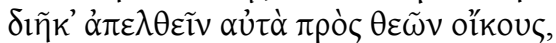

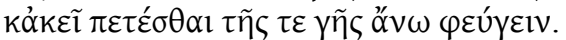

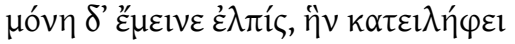

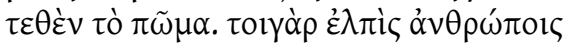

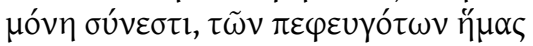

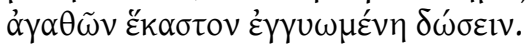

En la misma tradición genérica de Esopo, Babrio retoma el mito: no podemos hablar, de hecho, de una revisión novedosa del mismo, pues ésta es, tan sólo, una reescritura en verso de la fábula esópica. El ya clásico trabajo de Panofsky, La caja de Pandora. Aspectos cambiantes de un símbolo mítico, se contenta con este tardío remedo del mito, al paso que, sin razón alguna, achaca al mismo Hesíodo una supuesta incorrección en su versión, dando a entender que existiría una lectura anterior a la hesiódica más próxima a la de los fabulistas: «Nos inclinamos a creer [...] — dice Panofsky (1975: 18) - que la fábula cincuenta y ocho de Babrio, en la que el hombre como tal (ó $v \theta \rho \omega \pi$ o $)$ toma el lugar de Pandora y la vasija contiene bienes en vez de males, refleja el sentido original del mito más claramente que la versión impuesta a la posterioridad por Hesíodo».

\footnotetext{
${ }^{4} 132$ Halm; 123 Chambry.

${ }^{5}$ Sobre el texto de Esopo, Morocho (1994: 106).

${ }^{6}$ Ed. Crusius.
} 
2.5. Macedonio Hipato (s. vI d.C.), AG. 10.71

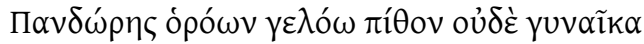

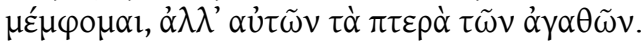

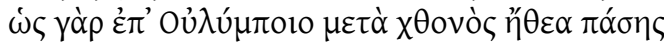

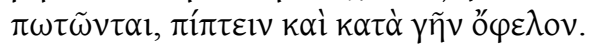

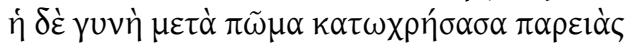

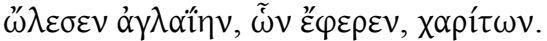

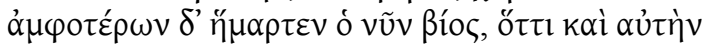

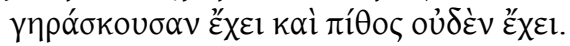

Damos nuestra traducción del epigrama:
Río al ver la tinaja de Pandora. Nada a la mujer reprocho, sino a las alas de los bienes; que cuando vuelan hacia las moradas del Olimpo, por los rincones de todo el orbe, a la tierra debian haber caido también. La mujer, en busca de la tapa, lividas sus mejillas, perdió el brillo de las gracias que portaba. De ambas carece la vida presente, pues a ella envejecida tiene, y nada la tinaja guarda.

En la tradición del epigrama, aquella tardía joya de la poesía griega, Macedonio mantiene algunos otros elementos narrativos clásicos: así, Pandora, la mujer, tiene su

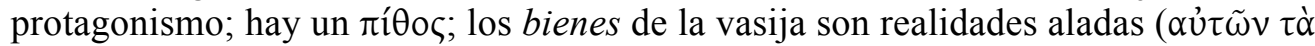
$\pi \tau \varepsilon \rho \dot{\alpha} \tau \tilde{\omega} \nu \dot{\alpha} \gamma \alpha \theta \tilde{\omega} \nu / \pi \omega \tau \tilde{\omega} \nu \tau \alpha \mathrm{l})$ : pero se invierten elementos claves de la narración, desarrollando motivos no hesiódicos acerca del contenido de la vasija: como ya otros habían obviado un aspecto básico del mito, quizá el más discutido, a saber: ¿cuál era la naturaleza de lo que contenía la vasija?, Macedonio sigue la versión optimista, pero para recaer en el pesimismo, pues estos abandonan a los hombres marchando al Olimpo. Pandora, por otro lado, recibe un tratamiento novedoso: de hecho, el primer dístico es una suerte de palinodia de la inveterada imagen, aborrecible, de Pandora: ella, aquí, no es la mala de la historia: Pandora ha sido burlada, pues los bienes - ante todo, la juventud, la belleza - también se han escabullido para ella, que quiso encerrarlos en la tinaja. En el estilo, incluso en el léxico, Macedonio traza pinceladas transparentes de su conocimiento y, por lo tanto, evidente referencia al relato hesiódico.

\subsection{Contaminatio de otros relatos secundarios}

La similitud de elementos narrativos e iconográficos puede llevar a la contaminatio del hipotexto original de un relato con otros textos que, estrictamente, no forman parte de su tradición, pero que pueden ser empleados por autores posteriores como fuentes secundarias para determinados motivos poéticos. Así, un pasaje homérico que, desde la Antigüedad, se puso en estrecha relación con el mito hesiódico es Ilíada 24.527- 
533: las palabras salen de la boca de Aquiles, quien intenta consolar al anciano Príamo, que se ha allegado ante él a solicitar el cuerpo de su hijo Héctor?:

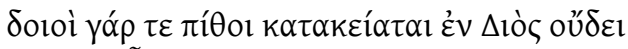

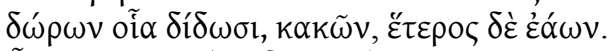

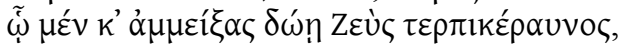

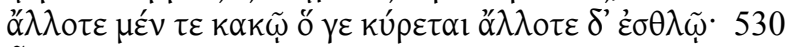

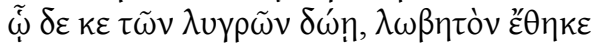

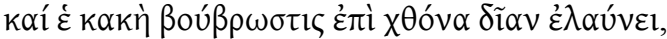

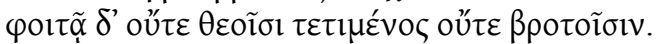

\begin{abstract}
Dos toneles están fijos en el suelo del umbral de Zeus:
uno contiene los males y otro los bienes que nos obsequian.

A quien Zeus, que se deleita con el rayo, le da una mezcla,

unas veces se encuentra con algo malo y otras con algo bueno.

Pero a quien sólo da miserias lo hace objeto de toda afrenta,

y una cruel aguijada lo va azuzando por la impía tierra,

y vaga sin el aprecio ni de los dioses ni de los mortales.
\end{abstract}

Partimos de lo apuntado por Plutarco sobre el contenido de la vasija hesiódica:

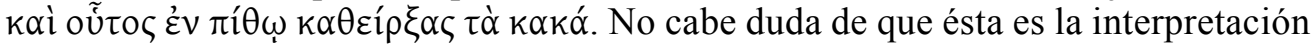
más ajustada a la narración que realiza el cantor de Ascra: males son, encerrados en una tinaja. Aquí radica la diferencia más reseñable entre ambos pasajes, dada la existencia de males y bienes, distintos y separados, en las dos tinajas homéricas. No podríamos negar, no obstante, que el esquema métrico de algunas partes del relato hesiódico puede desprenderse fácilmente del de la Ilíada, y precisamente en el punto de mayor desacuerdo narrativo: así, la unidad de la vasija en Hesíodo

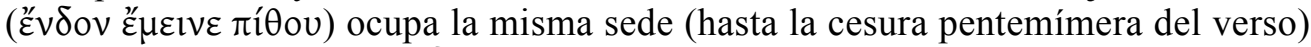

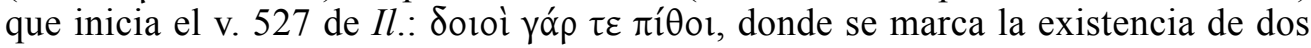
recipientes.

Tampoco son coincidentes los $\delta \tilde{\omega} \rho \alpha$ que ofrecen las tinajas: en Homero, se aguarda, como deseable, la mezcla de $\kappa \alpha \kappa \tilde{\omega} v /$ żá $\omega v$; en Hesíodo, los $\delta \tilde{\omega} \rho \alpha$ (implícitos en el

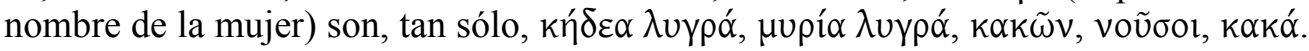

${ }^{7}$ Compara ambos lugares, por ejemplo, Plutarco, Consolatio ad Apollonium 105b-e ed. Babbitt: ó

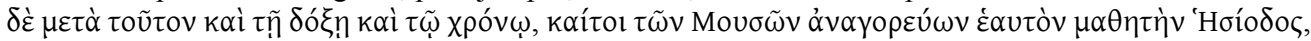

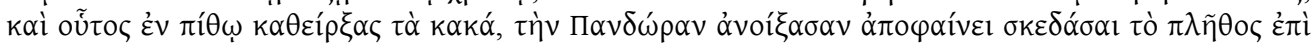

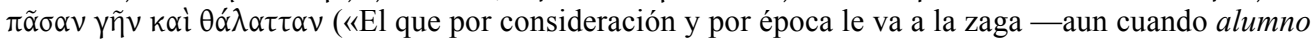
de las Musas se proclamara a sí mismo-. Hesíodo, tras haber encerrado los males en la tinaja, presenta a Pandora abriéndola y diseminándolos en su totalidad sobre la tierra y la mar toda»). Temistio

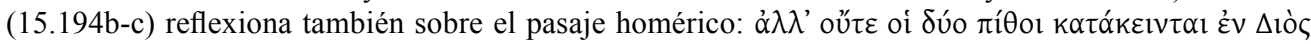

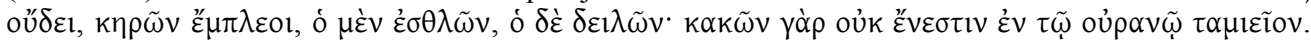

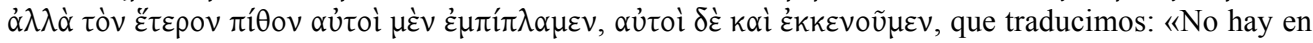
el umbral de Zeus dos tinas, llenas de Keres: una de buenas; otra de malas. Porque en el cielo no hay lugar para guardar males. Somos nosotros mismos quienes, unas veces, llenamos una; nosotros mismos quienes la vaciamos».

${ }^{8}$ Trad. Crespo (2000: 497-498). 
No deja de ser llamativo, sin embargo, el intento de conciliación con la tradición ho-

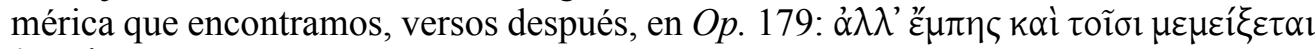

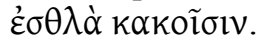

Tangencial es, por otro lado, la relación que en la Edad Media y el Renacimiento se hizo, probablemente, entre el relato de Pandora y el de Psique en Apuleyo (Metamorph. 6.19-21):

[...] 'sed inter omnia hoc obseruandum prcecipue tibi censeo, ne uelis aperire uel inspicere illam quam feres pyxidem uel omnino diuince formonsitatis abditum curiosius temptare thensaurum.' [...] et repetita atque adorata candida ista luce, quanquam festinans obsequium terminare, mentem capitur temeraria curiositate et: 'ecce' inquit 'inepta ego diuince formonsitatis gerula, quce nec tantillum quidem indidem mihi delibo uel sic illi amatori meo formonso placitura', et cum dicto reserat pyxidem. nec quicquam ibi rerum nec formonsitas ulla, sed infernus somnus ac uere Stygius, qui statim coperculo releuatus inuadit eam crassaque soporis nebula cunctis eius membris perfunditur et in ipso uestigio ipsaque semita conlapsam possidet. et iacebat immobilis et nihil aliud quam dormiens cadauer. sed Cupido iam cicatrice solida reualescens nec diutinam suce Psyches absentiam tolerans per altissimam cubiculi quo cohibebatur elapsus fenestram refectisque pinnis aliquanta quiete longe uelocius prouolans Psychen accurrit suam detersoque somno curiose et rursum in pristinam pyxidis sedem recondito Psychen innoxio punctulo sagittce suce suscitat et: 'ecce' inquit 'rursum perieras, misella, simili curiositate $[\ldots]^{\prime}$.

No podemos plantear una relación intertextual directa con los textos-fuente básicos del mito pandórico, pues el argumento de Apuleyo difiere diametralmente de aquél; sin embargo, la escenografía es evocadora: una figura femenina (Pandora / Psique) recibe una vasija ( $\pi i ́$ Ó / pyxis) con un contenido secreto y vedado; la curiosi-

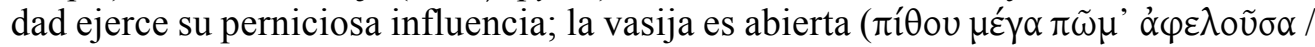
reserat pyxidem); terrible se muestra, en volatil irrupción, lo que guardaba la vasija ( $\dot{\varepsilon} \xi \dot{\xi} \pi \tau \eta$ / statim coperculo releuatus inuadit eam); la vasija, finalmente, es cerrada

${ }^{9}$ «Sobre todas las demás cosas, has de tener en cuenta - te lo advierto con la mayor escrupulosidad - sobre todo una: que no debes abrir ni indagar lo que contiene la caja que lleves, por más que te tiente la curiosidad de conocer el arcano tesoro de la hermosura divina [...]. Al volver a ver, y venerar otra vez la luz, aunque llevaba prisa en acabar con el encargo, se sintió tentada por una temeraria curiosidad: - Qué boba: llevar como llevo la hermosura divina, y no soy capaz de ponerme un poco para gustarle más a mi amante. Y diciendo esto, destapó la caja. Pero allí dentro no había ni rastro de hermosura, sino una adormidera realmente infernal, un sueño estigio, que, en cuanto se levantó la tapadera, la invadió, recubriéndole de una tan espesa niebla de sopor todos sus miembros, que la dejó sin sentido sobre el propio camino en la posición de marcha. Se quedó tan inmóvil que no parecía otra cosa que un cadáver dormido. Cupido, que con la herida cicatrizada había recuperado ya las fuerzas, no podía soportar por más tiempo la separación de su Psique, y se escapó por el tragaluz más alto de la habitación donde le habían encerrado - una vez que recobrara el vigor de las alas, después de descanso tan dilatado-, y se marchó volando hasta Psique, recogió la adormidera que se volatilizara por la curiosidad de la muchacha, y la volvió a meter en la caja. A ella la despertó con la inofensiva punzada de sus flechas y le dijo: — ¡Necia! ¡A poco te echa a perder otra vez tu curiosidad! [...]» (Royo, 1995: 169-170). 
de nuevo, ¿por la propia Pandora, en Hesíodo?; en Apuleyo, por Cupido ( $\pi \rho o ́ \sigma \theta \varepsilon v$

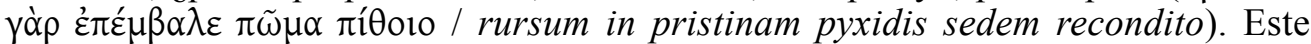
relato se convierte, no obstante, en un falso hipotexto para un motivo iconográfico importantísimo en el mito: la vasija: «La tinaja de Pandora parece haberse convertido en caja después de la época clásica, debido a una confusión con la caja que Psique tenía prohibido abrir en el historia del Asno de oro de Apuleyo» (Howatson, 1991: 682).

\section{PANDORA: FUENTES SECUNDARIAS DEL SIGLO XVI}

\subsection{Traducciones latinas de autores griegos}

Una traducción es ya parte de la tradición de un texto antiguo. Las primeras traducciones de la literatura griega llegan de la mano de los más avezados eruditos del primer Renacimiento, y éstas toman el latín como lengua. A modo de paradigma, reproducimos una de las versiones en lengua latina que más fortuna tuvo desde mediados del s. XVI en toda Europa: junto al texto griego de Hesíodo - difícilmente accesible a los castellanos de la época- pudo ser leído por nuestros autores:

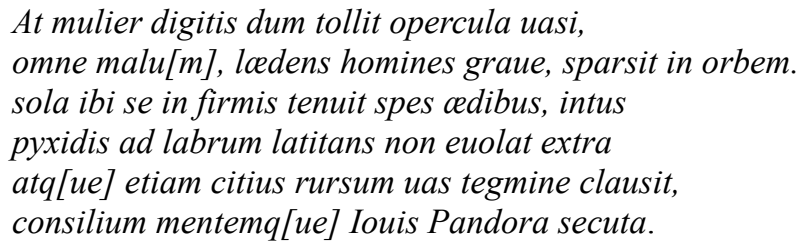

At mulier digitis dum tollit opercula uasi, omne malu[m], loedens homines graue, sparsit in orbem. sola ibi se in firmis tenuit spes adibus, intus pyxidis ad labrum latitans non euolat extra atq[ue] etiam citius rursum uas tegmine clausit, consilium mentemq[ue] Iouis Pandora secuta.

Iohannes Vlpius Franekerensis Frisius (1539: fol. A8 $8^{\mathrm{r}}$, p. 15).

\subsection{Comentarios}

La tarea de glosa y comentario se convierte en el Renacimiento en un arte en sí misma. Los volúmenes de la época, cuando no contienen impresas infinitas notas de eruditísima sabiduría, nos han llegado cubiertos con las más abundantes anotaciones a pluma de los que leyeron y estudiaron aquellas obras. Un ejemplo de ello lo encontramos en el Commentarius de Stephanus Riccius (Stephan Reich) sobre Hesíodo (1590: fol. $\mathrm{K} 1^{\mathrm{r}}$ ): en esencia, mantiene la lectura clásica del mito, apuntando hacia el significado más humano del mismo:

Ha sententice \& si quce extant similes, cum hoc Hesiodi figmento consentiunt. quod enim in summo labro Pandorce Pixidis sola spes hoserit, reliquis omnibus morbis euolantibus, monent spem omnium malorum extremum refugium atq[ue] solatium esse. nemo enim obrutus est malis, quin speret meliorem fortunam. 


\subsection{Léxicos}

La importancia del léxico redactado por el agustino italiano Ambrosius Calepinus ha sido destacada por $\operatorname{los} \operatorname{críticos}^{10} \mathrm{y}$, sin duda, pudo estar en las manos de los literatos castellanos como uademecum para consultas sobre aspectos como los mitográficos. Así, sobre Pandora, el lema de Calepino dice (1513: fol. ccxxiii, s. u. Pandora):

Pandora q[ua]si o[mn]i[u]m dona uel q[ua]si ab o[mn]ib[us] donata uel o[mn]i[u]m reru [m] genere donata. quo no[m]i[n]e etia[m] dicta est gens in [con]uallib[us] Indice, sicut li. uii. scribit Pli., quae duce[n]tis annis uiuit in iune[n]tute capillos ca[n]didos $h$ [abens], in senectute nigros.

El de Hermannus Torrentinus (1510: 138, s. u. Pandora) enfatiza el matiz pernicioso para los hombres de una Pandora hermosa y colmada de dones divinos:

Pandora, mulier formosissima [et] gratiosissima cui singuli dii sua dona dederu[n]t. [...] Pallas sapi[enti]am, Venus decore[m], Apollo musica[m], Mercuri[us] eloq[ue]ntiam. [...] ha[n]c (ut ait Hesiodus) Iupiter in terra [m] misit ut homines decip[er]et.

Conradus Gesnerus (1543: s. u. Pandora) compendia los léxicos al uso de la época, dando un cuadro muy completo de la historia:

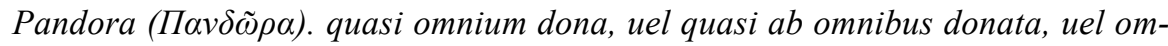
nium rerum genere donata. mulier fuit formosissima, a Vulcano Iouis iussu facta, cui singuli Dii sua munera dederunt, unde \& nomen sumpsit: scilicet Pallas sapientiam, Venus decorem, Apollo musicam, Mercurius eloquentiam. hanc, ut ait Hesiodus, Iupiter in terram misit ut homines deciperet: eo quod Prometheus ignem e calo abstulisset, ad Epimetheum ${ }^{11}$ cum pyxide clausa missam fuisse fabulantur. qui illa recepta, \& pyxide aperta, cui omne malorum genus inerat, terram morbis calamitatibusque repleuit. est \& nomen matris Deucalionis a qua Thessalia Pandora dicta est. hoc nomine dictce sunt gentes in conuallibus Indice, quce, ut ait Plinius libro septimo, capite tertio, ducentos annos uiuunt, in iuuentute capillos candidos habent, in senectute nigros.

${ }^{10}$ «Desde la primera edición de 1502 y unas primitivas equivalencias latinas, griegas e italianas, el Calepino fue incorporando sucesivamente más y más lenguas, después el español, el francés, el alemán, etc., hasta once, consiguiendo con ello la antonomasia de diccionario políglota» (Bécares, 1994: 111).

${ }^{11}$ El protagonismo de Epimeteo en la recreación del mito es claramente ascendente a lo largo de los siglos. Valga como ejemplo una obra no literaria: un grupo escultórico atribuido a El Greco (1541-1614) que se conserva en el Museo del Prado (Madrid): lo forman dos figuras, masculina y femenina, interpretadas como Epimeteo y Pandora; la vasija, en la tradición del pyxis, aparece como único elemento iconográfico indudable (en esta obra, en los brazos de Epimeteo, aparentemente de su propiedad; no sabemos si al mirar a la mujer alberga la intención de hacerla partícipe del objeto). Pandora — potente imagen de notable talla y fuertes miembros - parece observar a Epimeteo, con gesto indiferente. 


\subsection{Repertorios mitográficos}

Complementarios a los léxicos para los poetas que quisieran ilustrar con fidelidad las referencias mitológicas de sus composiciones, se redactan también en estos siglos numerosos repertorios mitográficos, auténticos manuales de la materia. Entre ellos, el de Lilius Grægorius Giraldus de Ferrara, Historiarum Deorum Syntagma (1580), en el que hallamos esta alusión a Pandora ${ }^{12}$.

Hanc (i. e. Pandora) a Ioue in terram demissa fingitur ut homines falleret et deciperet [...] hanc igitur [...] Iupiter cum pyxide pulcherrima illa quidem sed intus omne calamitatum genus abscondente ad Prometheum misit.

\subsection{Gnomológicos}

Las $\gamma v \tilde{\omega} \mu \alpha 1$, el prouerbium o adagium es género fértil de la literatura desde la Antigüedad. En la Europa de la Imprenta, infinitos fueron los volúmenes que recogían esta condensada pieza de sabiduría moral, humana y asequible, sin necesidad de excesivas glosas. Uno de los humanistas que más aportó al género fue Erasmo (1466-1536), quien no sólo hizo su propia colección (sus afamadas Adagiorum Chiliades), sino que enriqueció con sus escolios las máximas del popular Cato Romanus: sobre uno de sus dísticos (2.25 «Rebus in aduersis animum submittere noli. / Spe [m] retine, una homine $[\mathrm{m}]$ nec morte relinq[ui] t») apunta el sabio holandés:

Cum fortuna sceuit sustine te ipsum animi fortitudine, ac serua rebus secu[n]dis, nec abiicias spem, quce sola nec morientem relinquit. quam diu enim anima est, spes est. et in pixide Pandorce sola spes in labro hoesit [...] ([1517]: fol. b4 $\left.{ }^{4}\right)^{13}$.

\subsection{Libros de emblemas}

En la vía de los gnomológicos, las colecciones de emblemas adquieren desde el s. XVI un éxito sin contestación: su carácter iconográfico, donde la alegoría de los elementos pictóricos era del gusto erudito de la época; y el cariz moralizante de sus interpretaciones literarias les auguraba una amplia difusión entre las clases letradas. En castellano, damos cuenta de un documento datado en 1604, «Pandora y lo que se le dio en guarda», emblema 38 de los Emblemas morales de Don Iuan de Horozco y Covarruvias, Arcediano de Cuellar en la santa Iglesia de Segovia, dedicadas a la buena

${ }^{12}$ Citado por Harrison (1900: 100).

${ }^{13}$ Franciscus Sanctius Brocensis, El Brocense (1523-1601), planteaba en sus Commentaria in Andrece Alciati Emblemata, nunc denuo multis in locis accurate recognita, cum indice copiosissimo (Londres, 1573) (ed. Mayans, 1776: 124) discutiendo la lectura erasmiana del mito: Erasmus in adagio Malo accepto stultus sapit narrat hanc fabulam, sed concise, \& qui uideatur innuere Epimetheum aperuisse pixidem (si pixis uocandum est uas illud, quod omnia mala continebat, \& non dolium) cum ipsa Pandora in domo Epimethei repertum uas aperuit. certe uerba Hesiodi non indicant uas illud posse Latine dici pixidem. 
memoria del Presidente Don Diego de Covarruvias y Leyva su tio, en Çaragoça: por Alonso Rodriguez, a costa de Iuan de Bonilla, 1604, lib. 2, fol. L2 ${ }^{\text {r }}$ p. 75 :

Una vasija en guarda dado avia de bienes y de males a Pandora Iupiter avisando que cumplia no descubrirla, mas no vio la hora de abrirla, con que buelan a porfia, los bienes a do el bien eterno mora, los males al infierno caminaron, y esperança y temor solos quedaron ${ }^{14}$.

Horozco se debe a Hesíodo en la creación de este motto para su emblema, si bien con tres desviaciones destacables: la vasija — que no describe Horozco — contiene una mezcla de bienes y de males; cuando salen de ella, no sobrevuelan tierra y mar, como en Hesíodo, sino que se encaminan al cielo — los bienes - o al infierno - los males; y, por último, la $\dot{\varepsilon} \lambda \pi i ́ \zeta$ hesiódica, la spes de las versiones latinas, se desdobla en Horozco en dos faces: una positiva, la esperanza clásica; otra negativa, el temor.

Herederas directas de la del italiano Andrea Alciato (1492-1550) fueron muchas de las colecciones de emblemas de esta época. Bernardino Daza Pinciano, por ejemplo, hace su propia versión del emblema de Alciato «In simulacrum Spei» en estos términos, que recogen toda la iconografía de este motivo del mito: «La figura de la Esperanza» (1540: fols. G5 ${ }^{\mathrm{r}}-\mathrm{G6}^{\mathrm{r}}$, pp. 105-107):

[Tercetos. Dialogo. Lettor. Esperança.]

L. Quien eres tu q[ue] a'l cielo estas alçada?

Con que pinzel fue fecha tu figura?

E. Elpidio me pintò. yo soy llamada

la Esperança que no ay cosa dura

que facil no la buelva y la enternezca.

L. Por que hizo verde (di) tu vestidura?

E. No ay cosa que por mi no reverdezca.

L. Por que las flechas de la Muerte ayrada

quebradas traes? E. Porque a'l bivo crezca

solamente Esperança, que acabada

la vida, que esperar acà no queda.

L. En la tinaja por que estàs sentada?

E. Volando el mal yo sola estuve queda:

${ }^{14}$ Horozco se tambalea en su versión, haciendo decir a Hesíodo lo que, creemos, nunca dijo, con una interpretación final moralizante de raíz cristiana: «Aunque es verdad que Hesiodo cuenta solamente auer encerrado Iupiter los bienes quando los dio a guardar a la Pandora, y que solo la esperança se quedo en los labios de la vasija, no estorua que se diga auer sido la junta de los males y de los bienes, y que auiendose desaparecido los unos y los otros, solo la esperança y temor quedaron en el mundo. [...] en esta vida solo hallaremos la esperança del bien que deseamos, y deuemos pretender, y el temor del mal, y del castigo eterno que deuemos huyr» (fol. L2 ${ }^{\mathrm{v}}$, p. 76). 
como lo canta d'el Ascręo la Musa.

L. Que ave es esa (di) tan mansa y leda?

E. Es la Corneja, que contino usa el dar buena Esperança, por que quando no es, dize serà con voz confusa.

L. Quien son los que te estan acompañando?

E. Cobdicia y Buen succeso, y van delante los q[ue] velando estan, y estan soñando.

L. Quien es esotra que con faz co[n] stante te mira y te acompaña y junta viene?

E. Es la que venga el mal en un instante, y solo da à sperar lo que conviene.

\subsection{Interpretaciones alegóricas o moralizantes}

La lectura alegorizante o moralizante de los textos clásicos grecolatinos fue habitual en Europa desde la Antigüedad tardía. Valga como recordatorio la interpretación mesiánica que se hizo de la cuarta Égloga de Virgilio ${ }^{15}$. Una interpretación alegórica del mito de Pandora es la de Fray Lorenço de Çamora (1605: $2^{a}$ parte, en la que se trata de la cayda de Adam, y de los males que de las malas mugeres proceden; Symbolo $1^{\circ}$ : de como procuro el demonio hazer a Eua a sus costumbres para engañar al hombre, §1, pp. 180-181), quien identifica a Vulcano con el Ángel Caído, o, por así decir, expulsado y despeñado del Olimpo-Cielo:

Éste es el que hizo la Pandora, este es el padre del primer me[n]tiroso, este (quiero decir) el q[ue] crio a sus pechos con la leche de la me[n]tira a nuestra madre Eua.

Por lo tanto, Pandora es, en esta interpretación, hija, nada menos, que del Diablo. Concluye Fray Lorenço, con erudita mención a Hesíodo, auctor por antonomasia del mito:

La Pandora, fue como dize Exiodo, que para ruyna del ho[m]bre la hizo Vulcano.

\section{PANDORA: SU RECEPCIÓN EN LA LITERATURA DEL SIGLO DE ORO}

\subsection{Baltasar Gracián, El Criticón}

Baltasar Gracián (1601-1658), figura ya adentrada en los primeros giros del Barroco, «es ingenio libresco, inspirado en libros y reelaborador de lugares antiguos. Sus obras son un repertorio que acoge anécdotas, episodios, agudezas y todo tipo de refe-

${ }^{15}$ Como afirma el profesor Cristóbal, los clérigos se encargaron de «cristianizar» a los autores paganos, como evidencia la expresión — debida a Teodulfo de Orleáns - : plurima sub falso tegmine uera latent (2003a: 3). 
rencias y evocaciones de poetas clásicos y modernos» ${ }^{16}$. Su formación cultural parece haberse sustentado, especialmente, en sus estancias en el palacio de su noble amigo Juan de Lastanosa, en Huesca, cuya casa había llegado a ser, según Correa (1971: xi), «una magnífica biblioteca, un museo de ciencias naturales, un gabinete de física completísimos para la época».

El Criticón (publicado entre 1651-1657, en tres partes) es un alegórico recorrido por las edades del hombre, ahíto de referencias mitológicas, simbolismos, fábulas morales. Los protagonistas son Andrenio y Critilo. La vida se presenta en un recorrido amargo en búsqueda de una irrealizable beatitud eterna. En el prólogo se explicitan los autores antiguos que le sirven de referencia: como afirma Gracián, en una nota de prístina declaración de la deuda hacia sus modelos, «en cada uno de los autores de buen genio he atendido a imitar lo que siempre me agradó»: Homero, Plutarco, Esopo, Heliodoro, entre los griegos; Séneca, Apuleyo, entre los latinos; Ariosto, Boccalini, entre los italianos; Barclay entre los ingleses ${ }^{17}$. Dejamos a un lado sus inevitables fuentes espirituales y teológicas: recordemos que Gracián era jesuita. El pasaje que recuperamos para la comparación, en prosa - no nos acercamos, con Gracián, al género poético que vio nacer el mito en la Antigüedad - dice así:

Contaban los antiguos que cuando Dios crió al hombre encarceló todos los males en una profunda cueva acullá lejos, y aun quieren decir que en una de las Islas Fortunadas, de donde tomaron su apellido; allí encerró las culpas y las penas, los vicios y los castigos, la guerra, el hambre, la peste, la infamia, la tristeza, los dolores, hasta la misma muerte, encadenados todos entre sí. Y no fiando de tan horrible canalla, echó puertas de diamante con sus candados de acero. Entregó la llave al albedrío del hombre, para que estuviese más asegurado de sus enemigos y advirtiese que, si él no les abría, no podrían salir eternamente. Dejó, al contrario, libres por el mundo todos los bienes, las virtudes, los premios, las felicidades y contentos, la paz, la honra, la salud, la riqueza y la misma vida.

Vivía con esto el hombre felicísimo. Pero duróle poco esta dicha; que la mujer, llevada de su curiosa ligereza, no podía sosegar hasta ver lo que había dentro la fatal caverna. Cogióle un día bien aciago para ella y para todos el corazón al hombre, y después la llave; y sin más pensarlo, que la mujer primero ejecuta y después piensa, se fue resuelta a abrirla. Al poner la llave aseguran se estremeció el universo; corrió el cerrojo y al instante salieron de tropel todos los males, apoderándose a porfía de toda la redondez de la tierra ${ }^{18}$.

El Criticón, Parte 1. ${ }^{a}$ : Crisi decimatercia: La feria de todo el Mundo.

Notamos las divergencias del pasaje de Gracián respecto al que consideramos clásico, esto es, el de Hesíodo:

\footnotetext{
${ }^{16}$ Menéndez (1999: 780).

${ }^{17}$ «A quien leyere», epístola que prologa la obra (ed. Correa, 1971: 7-8).

${ }^{18}$ Ed. Correa (1971: 211-212).
} 
- Personajes: ausencia de Epimeteo y, sobre todo, del nombre de Pandora: es sustituida por la mujer, en antonomasia de notable misoginia ( $c f r$. «y sin más pensarlo, que la mujer primero ejecuta y después piensa»).

- Iconográficas: cueva en lugar de tinaja; puertas de diamante y candados de acero frente a la simple tapa.

- Estructura: en Hesíodo, todos los males están en la vasija; en Gracián, los males están encadenados todos; los bienes, libres. En ello vemos la influencia de textos emblemáticos y versiones tardías del relato.

- Ausencias: la referencia a la esperanza.

- Innovación: el escenario del encierro de los males: la vasija, olvidada, se trasforma en un lugar, las Islas Fortunadas ${ }^{19}$.

\subsection{Calderón de la Barca, La estatua de Prometeo}

Entre las obras dramáticas de Don Pedro Calderón de la Barca (1600-1681), aunque tenidas por menores, se encuentran muestras de comedia de temática mitológica, de gran riqueza escénica y musical, muy del gusto cortesano. Una de ellas, La estatua de Prometeo $^{20}$, es una recreación de la leyenda de Pandora, si bien pone el énfasis en otro de los actores del mito, a saber, en el Titán Prometeo. A esta comedia ligera, salpicada de coros de zagales y zagalas que cantan y danzan, habría que unir las que Calderón titula La púrpura de la rosa - sobre el mito de Venus y Adonis- y, sobre todo, La fiera, el rayo y la piedra - acerca de la intervención del Amor, Cupido, en tres mitos: el de Pigmalión, el de Irífile y el de Anaxárete ${ }^{21}$.

La libertad con la que Calderón de la Barca se acerca al mito de Pandora no es, sin duda, síntoma de desconocimiento de las fuentes más fidedignas, sino de genio poético y dramatúrgico: como afirma el profesor Cristóbal, «la libertad de recreación de los mitos propia del drama, puede, a su vez, responder a criterios ideológicos o de economía y tópica teatral $»^{22}$.

Ambientada en el monte Cáucaso, la comedia, escrita en octosílabos, se desarrolla a lo largo de tres Jornadas. Prometeo no es una divinidad. Movido por «el anhelo de saber» (jorn. 1, esc. 2) ha viajado a Siria a aprender de los caldeos astronomía y ciencias, de las que ha querido, sin conseguir sino desprecio, hacer partícipes a todos los hombres. Prometeo se presenta desolado, pasando su vida en contemplativo retiro en una cueva, donde estudia y cultiva las artes, en especial las que le inspira Minerva. Como don a la diosa, esculpe con barro una escultura de ella. Se produce la teofanía de la diosa (jorn. 1, act. 5) que, en agradecimiento, ofrece a Prometeo un deseo: vuelan juntos al cielo.

Calderón desdobla a la clásica diosa Atenea en dos personajes diferentes: Minerva y Palas, que se presenta en escena (jorn. 1, esc. 7), aclarando a los espectadores lo que la diferencia de su hermana:

${ }^{19}$ Como apunta el editor de Gracián, Fortunadas mantiene aquí su valor etimológico próximo al latín, por lo que, en realidad, estas islas harían referencia al infortunio, a la desdicha (Correa, 1971: 211, nota $a d l o c$.).

${ }^{20}$ Seguimos la edición de Hartzenbusch (1863: 701-718). No se nos da la fecha de estreno de la obra.

${ }^{21}$ Sobre estas obras, Menéndez (1999: 458-459); Cristóbal, (2003b).

${ }^{22}$ Cristóbal (2003b: 76). 
Pálas:

[...] gozando
tan una la infancia nuestra,
que el número no podía
distinguirnos; de manera
que ya hubo quien dijo
que equívocas eran
ó Minerva ó Pálas
una cosa mesma.
En valor y hermosura,
en majestad y grandeza
nacimos las dos conformes;
crecimos las dos opuestas
en los divididos genios
de nuestras dos influencias:
blanda ella lo diga,
dígalo soberbia
yo, dictando lides,
dictando ella ciencias.

Prometeo es el protegido de Minerva; Epimeteo, rudo, agreste cazador, lo es de Palas. De ella recibirá la orden de destruir la estatua realizada por Prometeo. Epimeteo (jorn. 2, esc. 1), que se ha prendado de la hermosura de la escultura («pues desde el instante que / vi maravilla tan rara, / idolatré su hermosura»), planea robarla, no destruirla, con la ayuda de un tal Merlin, chistoso villano, que con humor le advierte: «Mas sobre esto, ¿no reparas / que Pálas se ofenda, y viendo / el que para ti la guardas, airada se vuelva en / Dios Palos la diosa Pálas?».

Mientras tanto, vuelve Prometeo a la tierra con un haz de rayos de sol que ha hurtado a Apolo, en clara reminiscencia del fuego del mito hesiódico. Prometeo pone el haz de luz en las manos de la estatua y ésta toma vida (jorn. 2, esc. 3): desorientada, la mujer desconoce aun quién es:

Estatua:

¿Quién soy yo, dioses, que he puesto el orbe en confusión tanta?

(Jornada 2, Escena 5)

Un apunte de erudición por parte de Calderón: la primera vez que cita el nombre de Pandora (jor. 2, esc. 10), aunque como epíteto de Minerva, desentraña etimológicamente la palabra, si bien con poca ciencia: «aclamándola con nombre / de Pandora, que en el griego / idioma, aquí significa / La providencia del tiempo» ${ }^{23}$.

${ }^{23}$ Los personajes más chocarreros, como Merlin, llamarán a la estatua-Pandora con nombres que, probablemente, son corrupciones vulgares que se oían entre el pueblo, como Pandorga o Pandorra (jor. 2, esc. 12). 
Después se introduce uno de los motivos básicos del mito clásico: la vasija y su contenido: puesto en boca de la diosa Discordia — convocada por Palas para castigar a Epimeteo-, el cuadro es muy ajustado al texto de Hesíodo:

Discordia:

\author{
Mi don le ofreceré en una \\ urna, que contenga dentro \\ los hados de la Discordia. \\ Con que en abriéndola, es cierto \\ que rota la cárcel, salgan \\ infestando el aire, envueltos \\ en venenosos vapores.
}

(Jornada 2, Escena 10)

No sólo los ecos hesiódicos resuenan en estos versos de Calderón; también escuchamos a Virgilio: [...] hic uasto rex Eolus antro / luctantis uentos tempestatesque sonoras / imperio premit ac uinclis et carcere frenat; [...] ac uenti uelut agmine facto, / qua data porta, ruunt et terras turbine perflant (AEn. 1.52-54; 82-83).

Se celebra una fiesta, en la que todos aportan regalos a Pandora — sutil etimología, sobre la escena-: Discordia también lleva su presente; Pandora lo abre:

Pandora:

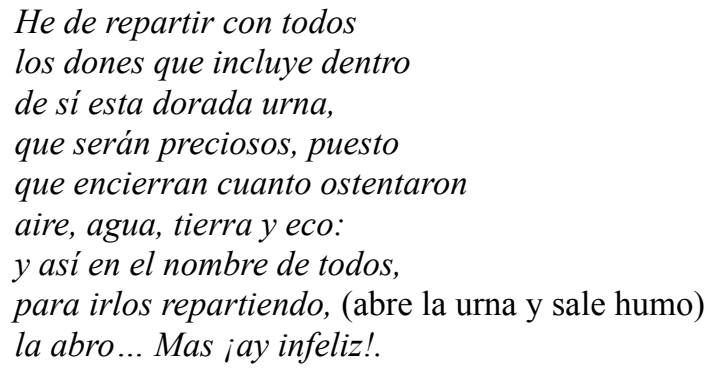

(Jornada 2, Escena 13)

Las sombras, la tormenta, el caos se apodera de la tierra. Pandora deja de ser, para todos, pero en especial para Prometeo, la hermosa y deseada imagen que había tomado vida:

Prometeo:

$$
\begin{aligned}
& \text { Eso sí... Mas nunca vengas } \\
& \text { tras mí, infausto monstruo bello; } \\
& \text { que al mirarte como causa } \\
& \text { de las ansias que padezco, } \\
& \text { te he cobrado tal horror, }
\end{aligned}
$$


tal sobresalto, tal miedo, tal susto, tal pavor, tal... no sé si aborrecimiento... que sin atreverme a verte me atrevo a dejarte. ¡Cielos!

(Jornada 2, Escena 14)

La comedia presenta, a continuación, una suerte de concilium deorum, en el que Apolo, todavía dolido por el robo de Prometeo, Palas y Minerva debaten sobre lo ocurrido (jorn. 3, esc. 1-2); los hombres, guiados unos por Epimeteo, otros por Prometeo, dedican sacrificios a una o a otra, en dos bandos divididos por Discordia. Tras unos diálogos llenos de equívocos con Minerva, con una nueva estatua que aparece y después desaparece, y con la propia Pandora (jorn. 3, esc. 4-9), la escena 11 describe la guerra entre los dos bandos, interpretada como lucha entre la razón y la fuerza. A este escenario llega Discordia como deus ex machina («Tened, parad los aceros»), decretando un final breve al conflicto con el castigo de Prometeo —en descripción esquilea-y la muerte de Pandora:

Discordia:

Que el agresor no más lo padezca

encarcelado en obscura prisión,

donde funesto pájaro sea

alado verdugo, que hambriento y feroz

su corazón despedace de día,

criando de noche otro igual corazón.

(Jornada 3, Escena 12)

Apolo, definitivo deus ex machina («Tened, parad, suspended el rigor»), se presenta en el momento preciso de detener la ejecución (jorn. 3, esc. 18), transformando la escena y, con ello, el final del drama, en una inesperada fiesta del triunfo del amor, con las bodas de Prometeo y Pandora.

\section{EPÍLOGO}

No podemos afirmar, sin duda, que Calderón, Gracián u otros autores del Siglo de Oro en España tuvieran conocimiento o acceso a la pléyade de fuentes que hemos intentado reseñar en las páginas precedentes; lo claro es que, con mayor o menor fidelidad a los diversos hipotextos que configuran la uulgata, por así decir, del mito de Pandora, acrecentada con la figura de Prometeo, los hombres de Letras de esta época disponían de una versión básica, con unos elementos narrativos convencionales, que pudieron reelaborar según su propio genio literario. Añoramos, pese a todo, que este 
relato, capital en el pensamiento griego, no fuera visitado y enriquecido con mayor esmero por los literatos de la época.

A modo de epílogo, y con el salto de siglos necesario, presentamos un soneto de D. Miguel de Unamuno, titulado, sin temor a desencadenar todos los ecos hesiódicos, «La tinaja de Pandora», fechado en Salamanca el 23 noviembre de 1910 y recogido en su Rosario de sonetos líricos ([1911]: 216):

No aun al mundo la segunda aurora

vierte en rosas envuelto su rocío

y nuestra madre ya, pobre Pandora,

pagando su hambre de saber, vacio

ve en sus manos el vaso que atesora

de la vida el secreto, y de él el río

de los males brotar. Y mientras llora

la ceguera fatal de su albedrio

y el loco anhelo de su pecho inquieto,

de su ciencia fatal como escurraja

la esperanza le queda, del secreto

consuelo triste que al mortal trabaja

engaño avivador, y es lo concreto

del vacio que guarda la tinaja.

Intelectual lectura del mito, en el que el conocimiento, «de la vida el secreto», parece ocupar el lugar de los traídos y llevados males del relato clásico. Un apunte del ilustre catedrático de griego dice así, estableciendo su recreación voluntariamente erudita de un relato que tan bien conocía: «Dice Hesíodo hablando de Pandora que 'solo quedó allí dentro de la tinaja en inquebrantable encierro la Esperanza hasta los bordes

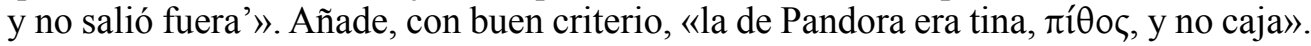

Un último texto nos lleva a Rubén Darío, «Salutación del optimista», 6-11 (Cantos de vida y esperanza). Muestra poética colmada de referencias clásicas - sibila, caja pandórica, Virgilio divino - que hace honor al mito y a la tradición literaria:

\footnotetext{
Retrocede el olvido, retrocede engañada la muerte;

se anuncia un reino nuevo, feliz sibila sueña

y en la caja pandórica de que tantas desgracias surgieron

encontramos de súbito, talismánica, pura, riente,

cual pudiera decirla en sus versos Virgilio divino,

la divina reina de luz, ;la celeste Esperanza!
} 


\section{REFERENCIAS BIBLIOGRÁFICAS}

Alciato, Andrea (1540), Los Emblema de Alciato, traducidos en rhimas Españolas. Añadidos de figuras y de nueuos Emblemas en la tercera parte de la obra. Dirigidos al Ilustre S. Iuan Vazquez de Molina [trad. Bernardino Daza Pinciano], Lyon: Mathias Bonhome, 1540.

BéCARES, Vicente (1994), «El Calepino y Nebrija», Voces 5: 111-117.

BeCKBy, Hermann (ed.) (1965-1968), Anthologia Graeca, Munich: Heimeran.

Brocensis, Franciscus (1766 [1573]), Commentaria in Andrece Alciati Emblemata, nunc denuo multis in locis accurate recognita, cum indice copiosissimo, en Francisci Sanctii Brocensis, in inclyta Salmanticensi Academia Emeriti, olim Rhetorices, \& primarii Latina, Graceeque Linguce Doctoris, Opera Omnia, una cum eiusdem scriptoris uita; auctore Gregorio Maiansio Generoso Valentino, Tomus Tertius seu Operum Philologicorum Pars Secunda, Geneuæ: apud Fratres de Tournes.

Calepinus, Ambrosius (1513), Ambrosius Calepinus Bergomates Dictionu[m] Latinarum e Greco pariter diriua[n]tiu[m] [...], Argentorati: opera Joannis Grun[n]inger.

Corbera, María Antonia (trad.) (1990), Hesiodo. Poemas hesiódicos, Madrid: Akal.

Correa, Evaristo (ed.) (1971), Baltasar Gracián. El Criticón, Madrid: Espasa-Calpe.

Crespo, Emilio (trad.) (2000), Homero. Ilíada, Madrid: Gredos.

CRISTÓBAL, Vicente (2003a), «Ovidio: del Arte de Amar a la alegoría moralizante», [Materiales del curso El Mundo Clásico en la Tradición Literaria (I): Edad Media y Renacimiento, Ponencias (I), Madrid: UNED: 1-23].

CRISTÓBAL, Vicente $(2003 b)$, «Pigmalión y la estatua: muestras de un tema ovidiano en la poesía española», $C F C(L) 23$, n. $^{\circ} 1: 63-87$.

Crusius, Otto (ed.) (1897), Babrii Fabulae Assopece, Lipsiæ: in ædibus B. G. Teubneri.

Chambry, Émile (ed.) (1925), Assopi Fabulce, Paris: Les Belles Lettres.

DARío, Rubén (1918), Cantos de vida y esperanza. Los cisnes y otros poemas. Ilust. Enrique Ochoa [vol. 7 de Obras Completas], Madrid: Ed. Mundo Latino.

Erasmus (trad.) [1517], Libellus elega[n]tissimus, qui inscribitur Cato de pr[a]eceptis uit[a] e co[m]munis, Erasmo Roterodamo castigatore, \& interprete, Louanii: Theodo. Martin. excudebat, [1517: trad. fechada en 1514].

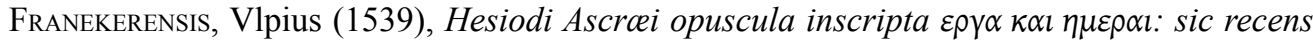
nunc Latine reddita, ut uersus uersui respondeat: una cum scholiis obscuriora aliquot loca illustrantibus Vlpio Franekerensi Frisio autore [...], Basileæ: apud Mich. Ising. (Michael Isingrin).

GeSnerus, Conradus (1543), Onomasticon propriorum nominum, uirorum, mulierum, sectarum, populorum, idolorum, syderum, uentorum, urbium, marium, fluuiorum, montium et reliquorum, ut sunt uici, promontoria, stagna, paludes, \&c. nunc primum cum ex Calepini, tum ex aliorum doctorum dictionariis partim a Conrado Gesnero Tigurino, partim ex eius amicis congestum, Basileæ: [s. $n$.].

Halm, Carl (ed.) (1889), Fabulae Assopica Collectce, Lipsiæ: in ædibus B. G. Teubneri.

HARrison, Jean Ellen (1900), «Pandora's Box», JHS 20: 99-114.

Hartzenbusch, Juan Eugenio (ed.) (1863), La estatua de Prometeo, en Comedias de Don Pedro Calderón de la Barca, Tomo 3, Madrid: M. Rivadeneyra, pp. 701-718.

Horozco, Juan de (1604), Emblemas morales de Don Iuan de Horozco y Covarruvias, Arcediano de Cuellar en la santa Iglesia de Segovia, dedicadas a la buena memoria del Presidente 
Don Diego de Covarruvias y Leyva su tio, en Çaragoça: por Alonso Rodriguez, a costa de Iuan de Bonilla, 1604.

Howatson, Margaret C. (1991), Diccionario de la literatura clásica, Madrid: Alianza (trad. esp.). MenÉndez, Jesús (coord.) (1999), Historia de la Literatura Española: vol. II: Renacimiento y Barroco, León: Everest.

Morocho, Gaspar (et alii) (eds.) (1994), Esopo y Babrio. Antología de fábulas griegas, León: Universidad de León.

Mynors, Roger (ed.) (1969), P. Vergili Maronis Opera, Oxford: University Press.

Panofsky, Dora \& Edwin (1975), La caja de Pandora. Aspectos cambiantes de un símbolo mítico, Barcelona: Barral (trad. esp.).

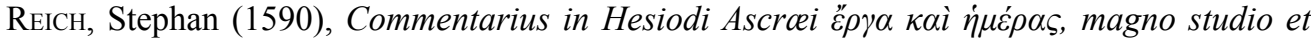
labore collectus, \& in usum studiosa iunentutis nunc primum editus a M. Stephano Riccio [...], Wittebergæ: imprimebat Mathæus Welack, impensis Iacobi Apelii.

Robertson, Donald S. \& Vallette, Paul (eds.) (1940-1946), Apulée: Les Métamorphoses, Paris: Les Belles Lettres.

Royo, José M. ' (trad.) (1995), Apuleyo. El asno de oro, Madrid: Cátedra.

[s. a.] (1542), Bona et mala, quibus in hac uita mortali genus humanum afficitur, ex S. Augustini libris de Ciuitate Dei, Moguntiæ: apud diuum Victorem excudebat Franciscus Behem., 1542 ,

SCHENKL, Heinrich \& Downey, Glanville (eds.) (1965), Themistii orationes qua supersunt, vol.

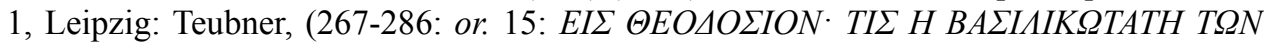
APETSN).

Solmsen, Friedrich (et alii) (eds.) (1970), Hesiodi. Theogonia. Opera et Dies. Scutum. Fragmenta selecta, Oxford: Oxford University Press.

Torrentinus, Hermannus (1510), Elucidarius carminu[m] et historiaru[m] uel Vocabularius poeticus co[n]tine[n]s fabulas, historias, prouincias, urbes, insulas, fluuios, et montes illustres. Item Vocabula et interpretationes Grecoru[m] et Hebraicoru[m], una cu[m] uocabulis co[m]munibus Saracenor[um] in Latinu[m] translatis, et aliis in fine adiu[n]ctis, Hagenaw: per industriu[m] Henricum Gran, impensis Joa[n]nis Rynman.

Unamuno, Miguel de [1911], Rosario de sonetos líricos, Madrid: Imprenta española.

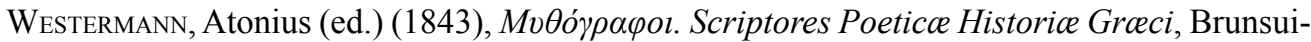
gæ: Georgius Westermann.

ÇAMORA, Fray Lorenço de (1605), Monarchia Mystica de la Iglesia, hecha de hieroglyficos, sacados de humanas y divinas letras: en que se trata de la composicion del cuerpo mystico de la Iglesia [...] Tratado del conocimiento propio, de la cayda del primer hombre, de las miserias de la humana naturaleza y de los efectos del pecado. Segunda Parte, Çaragoza: Alonso Rodriguez, a costa de Juan de Bonilla. 